\title{
Evaluating Malaysian Landscape Architecture Project Issues Controllability Level
}

\section{Adam Aruldewan S.Muthuveeran 1, Osman Mohd Tahir 1, Mohd Azren Hassan ${ }^{2}$, Hidayati Ramli ${ }^{3}$}

\author{
${ }^{1}$ Faculty of Design and Architecture, Universiti Putra Malaysia, Malaysia \\ ${ }^{2}$ Faculty of Architecture, Planning and Surveying, Universiti Technology MARA, Malaysia \\ ${ }^{3}$ Faculty of Engineering and Environment, Northumbria University, United Kingdom \\ aruldewan@upm.edu.my; osmanmt@upm.edu.my; azren446@uitm.edu.my; hidayati.ramli@northumbria.ac.uk
}

Tel: +60397694090

\begin{abstract}
The study's purpose is to assess project issues' controllability and indicate the necessity for a management system in Malaysian landscape architecture projects. A semi-structured interview with twenty-four Klang Valley landscape architects was utilised to collect data. The acquired material was analysed using content and thematic analysis. The study discovered that project issues could be managed if anticipated and addressed in advance. Despite this, inaction on common issues continues to affect project outcomes negatively. The study recommends developing a procedure for forecasting, evaluating, and treating future concerns.
\end{abstract}

Keywords: landscape architecture; project issues; controllability; management system

eISSN 2514-751X @2021. The Authors. Published for AMER ABRA cE-Bs by e-International Publishing House, Ltd., UK. This is an open access article under the CC BY-NC-ND license (http://creativecommons.org/licenses/by$n c-n d / 4.0 /)$. Peer-review under responsibility of AMER (Association of Malaysian Environment-Behaviour Researchers), ABRA (Association of Behavioural Researchers on Asians, Africans, Arabians) and cE-Bs (Centre for Environment-Behaviour Studies), Faculty of Architecture, Planning \& Surveying, Universiti Teknologi MARA, Malaysia.

DOI: https:// 10.21834/ajebs.v6i19.391 


\subsection{Introduction}

Landscape architecture projects are considered dynamic, with various obstacles arising from the projects' intrinsic ambiguity and complexity, resulting in a slew of issues. The project's methods, environment, and stakeholders all contribute to the project's failure due to this situation. Before a project's outcome is jeopardised, issues must be anticipated and addressed. In Malaysia, landscape architecture projects are a subset of the construction sector known for dealing with a wide range of project issues. Due to poor management of project issues before construction, construction projects in Malaysia face schedule and time overruns (Adnan \& Rosman, 2018; Fadzil et al., 2017; Goh \& Abdul-Rahman, 2013; Jusoff et al., 2008). Landscape architects are liable for serious bodily injury and property damage caused by their professional services under professional regulatory indemnity (Schatz, 2003; Williams, 2019). According to Ansah, Sorooshian, Mustafa, and Duvvuru (2016), even a little or basic project can run into complications due to the engagement of two different parties. Although project managers cannot forecast the future, they can anticipate and handle project issues before they become a project (Ansah et al., 2016; Tserng et al., 2009)

These dangers turn into project issues, influencing the project's quality, cost, schedule, scope, and goals (Farooq et al., 2018; PMI, 2017; Razi et al., 2020). Preliminary findings suggest that landscape architects can anticipate project issues as practitioners of landscape architecture. The scope of practice, which includes all phases of work during a project, requires the practitioner's knowledge base to be expanded (Hasan et al., 2018). They can also suggest control strategies to avert any potential project issues. Project issues continue to arise, regardless of their capabilities, due to inadequate problem-solving. Landscape architecture projects are the principal source of revenue for a landscape architectural firm. Failure to accomplish project goals will harm the company's financial performance, operations, culture, and reputation (Abdul-Rahman et al., 2015). Understanding the controllability of present project issues is essential for the project practitioner to plan the activities needed to manage and control these project issues in the future (S.Muthuveeran et al., 2020). Landscape architecture projects are seen as dynamic, with a wide range of outcomes and challenges arising from the projects' intrinsic ambiguity and complexity, leading to a slew of issues. The project's methods, environment, and stakeholders all contribute to the project's failure due to this situation. As a result, issues must be foreseen and addressed before jeopardising the project's success. On the other hand, this project focuses on controllability issues directly relevant to Malaysian landscape architecture projects and has gotten little attention in the literature.

As a result, this study aims to assess the controllability of project issues and determine the necessity for a management system in Malaysian landscape architecture projects. The goal is to document project issues that have occurred, evaluate the project's ability to control project issues, and assess whether a management system is required to control project issues. 


\subsection{Literature Review}

\subsection{Project Issues Definition}

Project issues are defined differently depending on the scope and sector of the project. Previously, PMI described an issue as "A point or matter that is in question or dispute, or a point or matter that is not settled or under discussion or over which there are opposing views or disagreements" (PMI, 2004, p. 363). Baker (2007, p. 3) defines an issue as "a gap between your actions and stakeholder expectations." Meanwhile, the Office of Government Commerce (OGC) defines an issue as "a relevant event that has happened, was not planned, and requires action" (OGC, 2009, p. 98).

Consequently, PMI defines a project issue as "A current condition or situation that may have an impact on the project objectives" (PMI, 2017, p. 709). In substance, PMI's definition is comparable to Projects In Controlled Environments (PRINCE2), which defines an issue as "A relevant event that has happened, was not planned, and requires management action. It can be any concern, query, request for change, suggestion, or off-specification raised during a project. Project issues can be about anything to do with the project" (PRINCE2, 2017, p. 376). Meanwhile, the APM in the United Kingdom takes a slightly different stance, stating a problem as "A threat to the project objectives that the project manager cannot resolve. Issues should be differentiated from problems, which are concerns that the project manager has to deal with on a day-to-day basis." (APM, 2006, p. 48).

In conclusion, any scenario or occurrence that has impacted the project's ability to achieve its objectives is defined as a project issue in this study. It is characterised by a misalignment between project outcome and stakeholder expectations. All project parties impacted by the project's outcome, including the serving professional landscape organisation, are considered stakeholders.

\subsection{Project Issues and Risk}

It is inappropriate to use "issues" and "risk" interchangeably. An issue is a historical occurrence or circumstance that has impacted or is now affecting the project's objectives, according to the Project Management Body of Knowledge (PMBOK). Meanwhile, the risk is an unpredictable event or situation with a favourable or unfavourable impact on the project's objectives (PMI, 2017). Risks are unpredictable, whereas issues are specific since they have occurred. After all, an event might not take place (APM, 2006). An event, obstacle, or difficulty is referred to as an issue. A risk is the prospect of losing something (Spacey, 2016).

Risks are often managed in a "future-focused" approach, whereas issues are typically addressed in a "present-focused" manner. Risk involves an element of uncertainty, whereas issues are unavoidable since they have already occurred. However, both issues and risks impact a project, which is why they must be controlled. 


\subsection{Project Issues' Controllability}

"A risk may have one or more causes and, if it occurs, one or more impacts," according to PMI (2004, p. 238). Though the reality is significantly more complex, one cause results in a single risk, which may have only one effect (Bugayenko, 2019; Hillson, 2018). Risk metalanguage effectively separates risk from its cause and consequence, as seen in Figure 1 (PMI, 2009, p. 29).

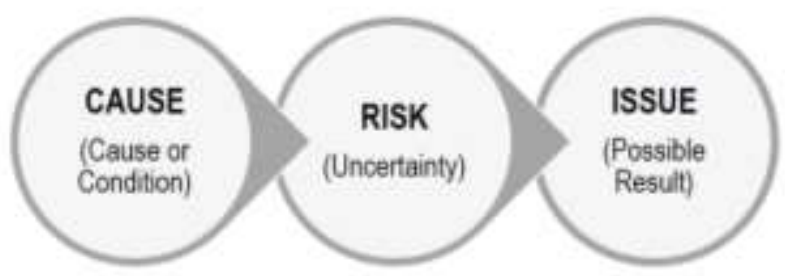

Figure 1: Relationship between cause, risk, and effect.

(Source: Extracted from PMI, 2009, p. 29)

An observable fact regarding the project's difficulties or surrounding environment is defined as a cause. At the same time, the risk is an unknown that, if realised, could jeopardise the project's goal (Hillson, 2018). Project issues are what happen as a result of risk. Because "a project risk that has occurred can likewise be deemed an issue," issues are relevant in the context of risk (PMI, 2009, p. 275). The comparison of risk and issues shows that proactive risk management can help mitigate project issues (Baker, 2007).

As a result, project issues can be managed and avoided. If issues are addressed sooner rather than later, they can be controlled more effectively. A future lesson learnt for the project will identify and document issues (PMI, 2017). If a project manager anticipates issues that develop due to a lesson learnt successful strategy, they can take effective action.

\subsection{Methodology}

Exploratory case analysis was used as part of the research technique. A preliminary investigation, data gathering, data analysis, and reporting are all part of the study's fourstage process ( illustrated in Figure 2). First, a preliminary investigation determines the study's context, need, gap, and goals. Second, twenty-four professional landscape architects in the Klang Valley were interviewed in a semi-structured interview. In keeping with the exploratory study, open-ended interview questions were pre-tested and asked in the form of an aide-memoire to provide respondents leeway and freedom to react (McNamara, 2017). The transcribed text, audio recordings, and project documentation were logged, and the research software, ATLAS.ti version 8.4.25, was recorded and organised. Finally, content analysis determines the codes, categories, and topics (Mayring, 2014). 

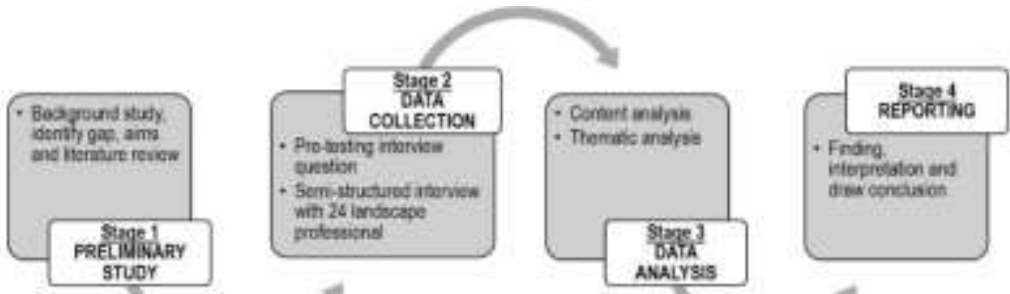

Figure 2: Study procedures

Themes were also interpreted and mapped using thematic analysis. The analysis comprises diving into the relationship between the categories and the theme, spotting patterns, and charting a course of action (Maguire \& Delahunt, 2017). Finally, the findings and interpretations are reviewed concerning project issues that have happened and project risk that has been projected. The conclusion is obtained from the objectives of the study.

Table 1: Respondents information

\begin{tabular}{|c|c|c|c|c|c|c|}
\hline \multirow[b]{2}{*}{ Respondent } & \multirow[b]{2}{*}{$\begin{array}{l}\text { Respondent's } \\
\text { Position }\end{array}$} & \multicolumn{2}{|c|}{ Respondent's Background } & \multicolumn{3}{|c|}{ Respondent's Organisation Background } \\
\hline & & Education & $\begin{array}{l}\text { a Years of } \\
\text { Experience }\end{array}$ & $\begin{array}{c}{ }^{b} \text { Years } \\
\text { Established }\end{array}$ & $\begin{array}{l}\text { 'Headcount } \\
\text { Size }\end{array}$ & $\begin{array}{c}{ }^{d} \text { Total } \\
\text { Ongoing } \\
\text { Project }\end{array}$ \\
\hline R01 & Director & Abroad & Expert & Established & Small & Medium \\
\hline R02 & $\begin{array}{l}\text { Project } \\
\text { Director }\end{array}$ & Local & Intermediate & Established & Small & Medium \\
\hline R03 & Director & Abroad & Expert & Established & Small & High \\
\hline R04 & Director & Local & Expert & Established & Small & Medium \\
\hline R05 & Principal & Local & Intermediate & New & Small & Low \\
\hline R06 & Director & Local & Expert & Established & Small & Low \\
\hline R07 & Director & Local & Intermediate & New & Micro & Medium \\
\hline R08 & Director & Local & Intermediate & New & Micro & Low \\
\hline R09 & Director & Abroad & Expert & New & Small & Low \\
\hline R10 & Director & Abroad & Expert & Intermediate & Small & Medium \\
\hline R11 & Associates & Local & Intermediate & Established & Small & Medium \\
\hline R12 & $\begin{array}{l}\text { Head of } \\
\text { Contract }\end{array}$ & Local & Intermediate & New & Small & Medium \\
\hline R13 & Director & Abroad & Expert & Intermediate & Small & Low \\
\hline R14 & Director & Local & Intermediate & New & Small & Medium \\
\hline R15 & Director & Local & Expert & Established & Small & Medium \\
\hline R16 & Director & Local & Intermediate & Intermediate & Micro & Medium \\
\hline R17 & Principal & Local & Intermediate & Intermediate & Small & Medium \\
\hline R18 & Director & Local & Intermediate & New & Micro & Low \\
\hline R19 & $\begin{array}{l}\text { Principal } \\
\text { Director }\end{array}$ & Abroad & Expert & Established & Small & Medium \\
\hline $\mathrm{R} 20$ & Director & Local & Intermediate & New & Small & Medium \\
\hline R21 & Director & Abroad & Expert & Established & Small & Medium \\
\hline
\end{tabular}


S.Muthuveeran, A.A., et.al./ Asian Journal of Environment-Behaviour Studies (ajE-Bs), 6(19) May / Aug 2021 (pp.27-42)

\begin{tabular}{|c|c|c|c|c|c|c|}
\hline R22 & $\begin{array}{l}\text { Managing } \\
\text { Director }\end{array}$ & Local & Expert & Established & Small & Medium \\
\hline R23 & Director & Local & Intermediate & New & Micro & Low \\
\hline R24 & Director & Local & Intermediate & Intermediate & Small & Medium \\
\hline Notes: & \multicolumn{6}{|c|}{ 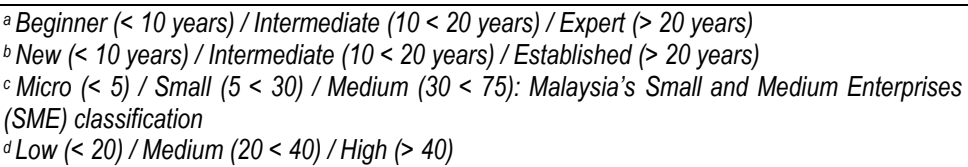 } \\
\hline
\end{tabular}

The landscape architecture organisation chose twenty-four respondents based on predefined sampling parameters. They were licenced landscape architects who worked for landscape architecture firms. In their current organisation, they held management and decision-making positions, indicating that they influenced policy and practice on the ground. All responders had at least ten years of experience in the field. As part of a complete cycle of landscape projects in an urban area in Malaysia's Klang Valley, they worked on various project sizes, locations, and scopes. Each respondent was given an alphanumerical code (R01-R24), and the information about each respondent is included in Table 1.

\subsection{Results}

\subsection{Project Issues That Occurred}

Respondents were asked for their thoughts on issues stemming from the project's difficulties. The interview input yielded 79 coded project issues, which were then grouped into six affected project objectives, as shown in Table 2.

Table 2: Feedback on landscape project issues and affected objectives from respondents

\begin{tabular}{lll}
\hline Respondents & Landscape Project Issues & Affected Objectives \\
\hline R09, R23 & $\begin{array}{l}\text { Project complexity and scope put the business under } \\
\text { financial pressure }\end{array}$ & Business \\
R05 & Additional Variation Order (VO) works not paid \\
R04, R09, R13, R17 & $\begin{array}{l}\text { Constant design change disrupt business operations } \\
\text { R09, R18 }\end{array}$ & Prolonged professional services from the agreed contract \\
R13 & Professional fees are underpaid \\
R12 & Project scope is reduced, affecting the service fees \\
R09 & Project stopped halfway \\
R02, R17 & Project outcome affects the business reputation \\
R04, R05 & The project did not follow the initially planned process \\
R05, R13, R21 & Internal operation disruption due to project undertaking \\
R09, R18 & Demotivated project team & \\
\hline R02, R06, R08 & Poor quality by the contractor & Quality \\
R06 & Contractor rushing to complete due to a tight deadline & \\
R13, R15, R17 & Low-quality material due to cost-cutting &
\end{tabular}




\begin{tabular}{|c|c|c|}
\hline R06, R10 & Planting damaged & \\
\hline $\mathrm{R} 03$ & Mechanical element malfunctioned & \\
\hline R08, R14, R24 & Underspecification & \\
\hline R17, R24 & Defect and redundant appearance & \\
\hline $\mathrm{R} 11$ & The degraded environment due to erosion & \\
\hline R03, R12, R19 & Rework cost due to defect & Cost \\
\hline $\mathrm{R} 05, \mathrm{R} 07$ & Additional work instructed by the client without payment & \\
\hline $\mathrm{R} 02, \mathrm{R} 10, \mathrm{R} 11, \mathrm{R} 22$ & Additional work and design change are unpaid & \\
\hline $\mathrm{R} 05, \mathrm{R} 21$ & Site damages by others lead to additional project cost & \\
\hline R09 & Complying with authorities' instruction for changes & \\
\hline $\begin{array}{l}\text { R01, R04, R11, R13, } \\
\text { R17, R20 }\end{array}$ & Client dissatisfied with project's physical outcome & $\begin{array}{l}\text { Stakeholders } \\
\text { Satisfaction }\end{array}$ \\
\hline $\mathrm{R} 03, \mathrm{R} 11, \mathrm{R} 22$ & Poor consultant servicing & \\
\hline $\mathrm{R} 02, \mathrm{R} 17$ & Poor design realisation due to too many amendments & \\
\hline $\mathrm{R} 01$ & $\begin{array}{l}\text { Holding back project CMGD approval and refused to close a } \\
\text { project }\end{array}$ & \\
\hline $\mathrm{R} 22$ & Contractor stopped working & Time \\
\hline R06 R20 & Late site mobilisation and site not ready & \\
\hline $\mathrm{R} 05, \mathrm{R} 08$ & Poor contractor scheduling & \\
\hline $\mathrm{R} 22$ & Frequent site instruction and additional work & \\
\hline R10, R11. R13 & Short timeline given & \\
\hline $\mathrm{R} 03$ & Prolonged CMGD clearance & \\
\hline R05, R13. R20 & Extensive VO & Scope \\
\hline R14 & $\begin{array}{l}\text { Damages to completed works - replacement not accordance } \\
\text { specification }\end{array}$ & \\
\hline $\mathrm{R} 02, \mathrm{R} 10$ & The client changed their mind & \\
\hline R13, R17 & $\begin{array}{l}\text { Cost-cutting practice by the client from the agreed sign-off } \\
\text { proposal budget }\end{array}$ & \\
\hline
\end{tabular}

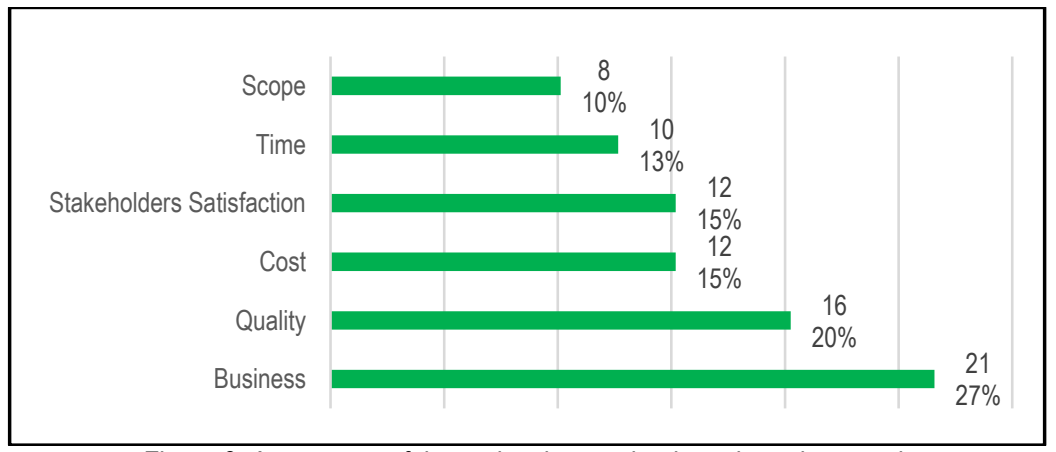

Figure 3: A summary of the project issues that have been impacted.

According to the research shown in Figure 3, the most critical issues impact the business goal. The most prevalent issues impeding the attainment of business objectives include constant design modifications, a tarnished business reputation, disruptions in 
internal operations, and demotivated project teams. Substandard contractor work, planting damage, and material misspecification, on the other hand, harm the most objective quality. Unpaid costs to the landscape architect for additional work and design changes are the most significant causes for the cost aim. Finally, significant Variation Orders (VO) and clients' frequent design and planning changes impact the scope aim.

\subsection{Predictability of Project Issues that Occur}

The capacity of respondents to forecast the 79 issues that arose during the project was tested. As seen in Figure 4, the data are divided into two categories: expected and unpredicted.

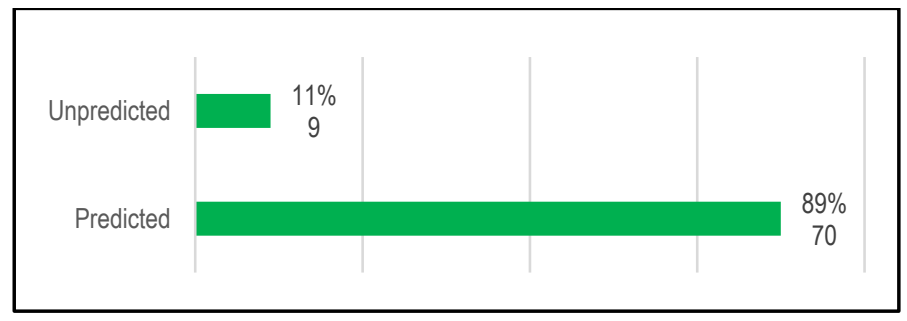

Figure 4: The predictability of project issues

According to the findings, $70(89 \%)$ of the 79 project issues could be forecast in advance, according to respondents. According to R03, R13, R15, and R23, project issues could be predicted based on substantial research and project team members' expertise. Surprisingly, specific technical issues, such as budget, technology, quality, and scope revisions, were foreseen early. The issues that were projected based on contractor input (R03, R20), team members' experiences (R04, R05, R15, R19), a competent project team (R02, R05), team project meetings and discussions (R05, R06), and forecasting (R06, R19). Most project issues, according to R13, can be predicted as early as the project's genesis stage. R05, R10, R11, R21, and R24 agreed that project issues should be identified early in the project's lifespan to be resolved before they have a detrimental impact on the project's conclusion. R11 emphasised the need to commit effort to the project's early stages because extra project information is needed to foresee issues.

Only nine $(11 \%)$ of the 79 issues that occurred were unexpected and unplanned. Environmental impact, site circumstances, new product application, team member turnover, economic instability, design market trend, price fluctuation, social-political climate, project members' personalities, and payment delay, according to R04, R07, R09, R11, R13, R14, R16, R17, and R21. Issues involving subjective matter, such as human, socio-cultural, and environmental repercussions, are difficult to predict, according to R08. Landscape scope, which necessitates design input and engagement with the environment, is more subjective than engineering projects, according to R17, leading to a high level of uncertainty and unforeseen occurrences. 
Because of the project managers' knowledge and ability to forecast, the bulk of project issues was anticipated. Objective technical issues that necessitate technology, engineering input, and a predictable scope Intangible issues such as the environment, design, and human personality, on the other hand, are more challenging to forecast, which may satisfy stakeholders

\subsection{Treatment For Project Issues That Have Been Predicted}

Respondents were questioned about how they planned to address the 70 issues that were predicted. As shown in Figure 5, the study identified three diverse behaviour patterns among respondents regarding the projected issues.

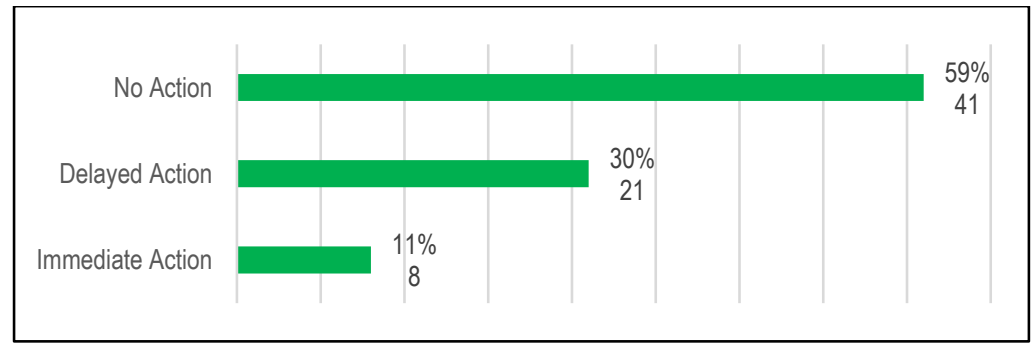

Figure 2: The steps taken to address the issues that were predicted

Only $8 \%(11 \%)$ thought that issues would be resolved right away. The steps performed mainly were aimed at preventing the projected issues from occurring, such as decreasing the scope and simplifying the design (R09, R15), minimising the maintenance effort (R04, R12), and changing the service agreement (R09, R12). R11 created a contingency fund, while R15 changed the project's operation. By shifting the scope, R22 was able to avoid the issues.

Second, 21 (30\%) projected issues were postponed by treating them when they happened. The majority of the activities aimed to reduce the project's negative issues. These include negotiating with the client to acquire additional monies and time allowances (R02, R19); monitoring, recording, and reporting to protect the consultant (R02, R03, R20, R21); and increasing communication (R11) (R10). Mitigation activities are conducted while dealing with contractors, such as passing liability to contractors and suppliers (R02, R03), monitoring the contractor (R06, R08, R09, R14, R17, R24), and changing the contract and operational method to reduce the impact of the issues (R22).

Third, most respondents $(41 \%)$ predicted the issues but did nothing about them. The project team was in charge of day-to-day operations. This action was taken because respondents had no other options, which was due to several factors, including the need to stay in business, the need to maintain client relationships (R01, R06, R07), the local authority's instruction (R17), the client's instruction (R08, R10, R18, R19, R23), and a time constraint (R14, R16). Because the project manager assumed they could be managed within the existing method, specific predicted issues were unanswered (R01, R06, R08, 
R24). According to R09, R17, R19, and R24, the issues were anticipated and will have little impact on the project's overall outcome. Meanwhile, R02, R05, R14, and R20 stated that they were aware of the looming issues but waited too late to solve them.

Despite its capacity to foresee previous issues, the evaluated project issues are almost certain to occur due to its tendency for passivity. Delayed action reduces the severity of the issues, but it does not eradicate them. It was decided that quickly addressing the projected issues was not the best course of action. This scenario explains why project issues persist.

\subsection{Suggested Treatment Strategy For Project Issues Predicted}

According to the developing finding, respondents could suggest a prospective treatment method for the project's issues. As shown in Table 3, their reactions are divided into four risk management techniques (PMI, 2017), avoidance, mitigation, transfer, and acceptance of the issues.

Table 3: Respondents' feedback on project issues treatment strategies

\begin{tabular}{|c|c|c|}
\hline & Treatment Strategies & Respondents \\
\hline \multirow[t]{13}{*}{ Avoid } & Close stakeholder engagement to obtain crucial information & R04, R07, R12 \\
\hline & Study the project background and stakeholders' requirement & R14, R16, R21, R23 \\
\hline & Seek information from the market & R16, R18 \\
\hline & Engage with other project parties & R01, R23 \\
\hline & Clarify requirements, seek a solution, and revise scope with client & $\begin{array}{l}\text { R01, R12, R16, R19, } \\
\text { R20 }\end{array}$ \\
\hline & Revise plan and operation & R08 \\
\hline & Change contractor & R01, R02, R11 \\
\hline & Seek alternative material & R04 \\
\hline & Extend the schedule & R19, R20, R23 \\
\hline & Increase the budget & R23 \\
\hline & Enhance communication and information management & R04, R12, R16, R19 \\
\hline & Remove the scope or decline taking up the project entirely & R04, R16, R18 \\
\hline & Regular review and meeting with the project manager and team & R08 \\
\hline \multirow[t]{5}{*}{ Mitigate } & Choose a more stable supplier & R01, R03, R15, R24 \\
\hline & Conduct more tests and built mock-up of new product & R03 \\
\hline & Reduce scope & $\begin{array}{l}\text { R03, R05, R06, R13, } \\
\text { R21 }\end{array}$ \\
\hline & Adopt a less complex design & R09, R14 \\
\hline & Good project management practice and employ an experienced manager & R01, R02, R09 \\
\hline \multirow[t]{4}{*}{ Transfer } & Engage a specialist for new technology and specialised scope work & $\begin{array}{l}\text { R03, R04, R07, R09, } \\
\text { R21 }\end{array}$ \\
\hline & $\begin{array}{l}\text { Generate a comprehensive contractual agreement - transfer liability to client } \\
\text { and contractor }\end{array}$ & $\mathrm{R} 14, \mathrm{R} 17, \mathrm{R} 23$ \\
\hline & Seek client's ownership of the project issues & R12, R16, R20, R21 \\
\hline & $\begin{array}{l}\text { Systematic documentation - shared communication and information } \\
\text { management }\end{array}$ & $\begin{array}{l}\text { R01, R03, R04, R08, } \\
\text { R11, R24 }\end{array}$ \\
\hline \multirow[t]{4}{*}{ Accept } & Leave to project operation to deal with issues & R10, R12, R23 \\
\hline & Document project issues & R07, R13, R17, R23 \\
\hline & Periodical review & R13 \\
\hline & Establish contingencies to time, budget, or resources & $\begin{array}{l}\mathrm{R} 01, \mathrm{R} 07, \mathrm{R} 17, \mathrm{R} 22, \\
\mathrm{R} 23\end{array}$ \\
\hline
\end{tabular}


As demonstrated in Figure 6, avoiding project issues is the preferred course of action $(42 \%)$. This technique was chosen when presented with project issues affecting the organisation's cost, time, and scope. When it comes to project quality issues, the ideal solution is to pass $(23 \%)$ the responsibility to other parties. This activity is understood as the contractor's and supplier's quality of work. As a result, the respondents shifted the blame to them.

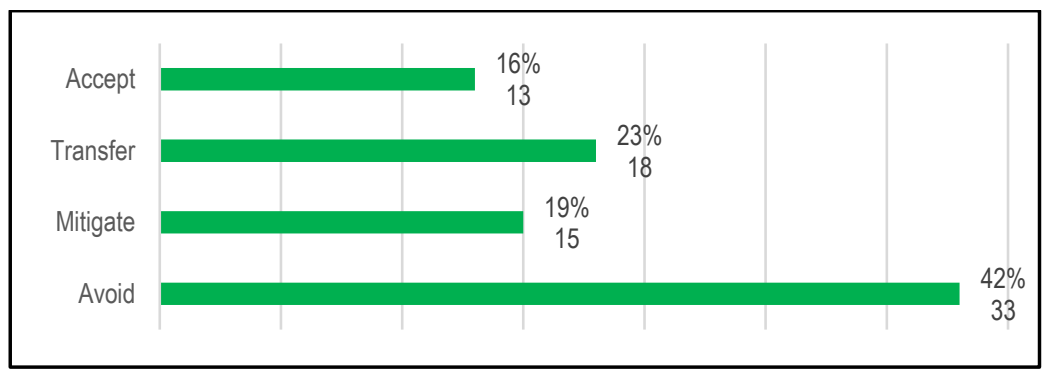

Figure 6: Suggested treatment techniques for occurring project issues

Meanwhile, accepting (16\%) project issues is the preferred course of action when the issues involve stakeholder displeasure. The technique was utilised when project issues were unavoidable; no options for lessening the impact existed, and the issues were not transferable to others. Given how unclear and difficult it is to manage stakeholder unhappiness, this behaviour is understandable. As a result, the responders allowed for project issues while closely monitoring them and preparing for contingencies.

The responses may recommend appropriate treatment options for the issues by preventing them, minimising their impacts, or shifting them to lessen their implications. It contradicts the initial action treatment described in part 4.3 that they choose to do nothing in the face of foreseeable issues. Further investigation is necessary to establish the explanations behind these phenomena of diverging actions.

\subsection{The Need for a Management System to Control Project Issues Beforehand}

The interviewer explained to the respondents that a projected occurrence that can cause an issue to arise is a project issue. The respondents' comments sought a management system to control the project issues in the future. Their responses were classified into three categories, as illustrated in Figure 7.

The majority, $71 \%$ of the respondents, highly agreed to a management system application to spot project issues earlier and manage them methodically. According to R02, $\mathrm{R} 05, \mathrm{R} 06, \mathrm{R} 15$, and R19, today, the projects rely on the project managers' experience to forecast and control the project issues. R01, R06, R12, and R15 added that the existing procedure leaves the projected project issues unattended and leaves it to the project operation and project manager's experience to deal with them. R12 and R15 indicated that, 
based on their experience, landscape projects do not manage issues efficiently compared to other industries.

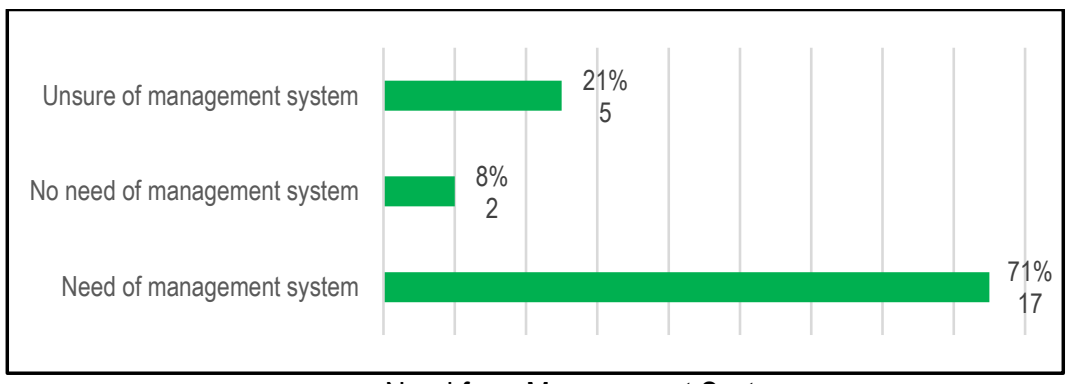

Figure 7: Need for a Management System

Only $2(8 \%)$ out of 24 respondents said that they did not need any new management system at the moment. They asserted that the existing operational approach was sufficient to manage the project issues beforehand. R17 said they relied on project managers' experience to tackle the project issues. Meanwhile, R20 was concerned that overdependence on a management system will be time-consuming, costly, and restrict corporate creativity. R20 remarked that the local industry's current culture and ethics would confine any management system structure.

The remaining five responders (R03, R07, R09, R16, and R23) were doubtful whether the management system application was needed at present. R07 and R23 expected actual management system testing before deciding its necessity.

\subsection{Discussion}

Generally, project issues can be avoided if the project can predict and treat them in advance. This result was confirmed through in-depth conversations with landscape professionals. The prediction and treatment actions (refer to subsections 4.2 and 4.3 ) and suggested treatment strategies (refer to subsection 4.4) for the actual project issues are summarised in Figure 7.

The project issues were predictable, related to the practical challenges, and identified stakeholder considerations. The research revealed that respondents predicted $89 \%$ of project issues in advance. Despite their ability to predict issues in advance, they did not resolve them. Only $11 \%$ of anticipated issues are addressed quickly, as indicated by the project manager. Over $59 \%$ of the projected issues were not addressed. It was allowed to occur and was left to the project operation team to resolve.

Additionally, the projects proposed a treatment method for each issue, proving their capacity to take immediate action rather than inaction. Effectively, $42 \%$ proposed disregarding the project's issues to remove them. Another alternative is to lessen the 
issues' impact by either minimising their repercussions (19\% ) or transferring their liability $(23 \%)$ to others. Only $16 \%$ proposed resolving project issues using contingency planning.

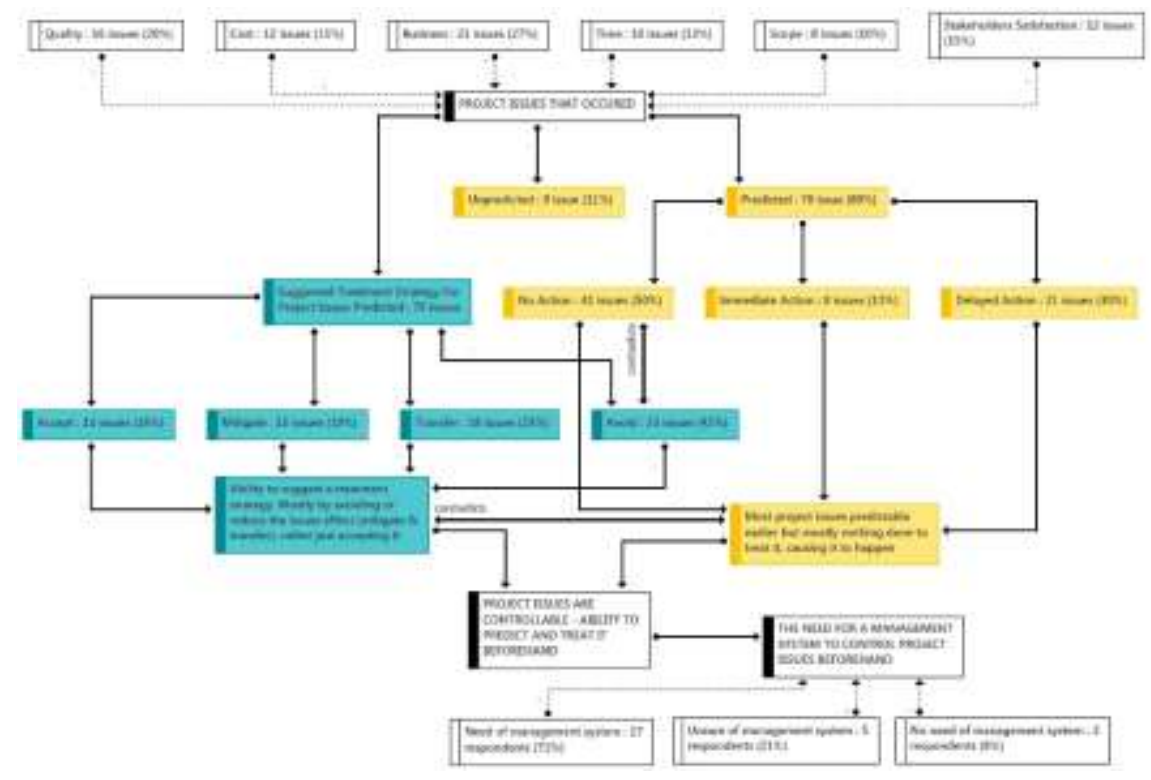

Figure 8: Controllability of project issues

The responders overwhelmingly agreed that the project issues were controllable. The findings reveal that landscape architecture projects are manageable by forecasting and recommending viable treatment techniques to manage the issues in advance. This finding validated the preliminary study findings and was confirmed by Hillson (2018). Spacey (2016) proposes that project issues are manageable by early prediction, strategising a treatment approach, and successfully implementing the strategy. However, the existing project culture suggests that despite their ability to forecast project issues, little quick action is made to remedy the issues and generally leave it to the project operation team to handle them. Adding to this phenomenon, despite the project's ability to recommend an appropriate treatment action by avoiding, minimising, and transferring the issues, this strategy was not appropriately applied during the project progression. This move caused project issues to happen repeatedly and impacted project performances. Bugayenko (2019), Hillson (2018), and PMI (2017) all concurred, noting that project issues are controllable with proactive risk management. Currently, the project is managed with more to issue-focused rather than risk-focused.

The study highlights the need for an effective management system for controlling the project issues beforehand. This proponent concluded by analysing the underachievement 
of projects' business objectives, the controllability of issues, and the interviews' responses (refer to subsections 4.5). An appropriate management system is needed to handle a project risk before it potentially becomes a project issue later. Although a professional landscape architect possesses excellent design and technical knowledge, a management system is needed to systematically warn them of potential issues, quantify the consequences, and determine appropriate actions to control the issues with the best available tools and techniques.

\subsection{Study Limitation}

The following are the study's limitations. First, the study limited the case study interviews to landscape architecture practitioners, although this was not intended to lessen the significance of other practitioners' viewpoints. Second, the case project issues revolved around a preference for urban landscape architecture as a backdrop; no other location was chosen. Thirdly, the study focused on project management within the landscape project lifecycle process, from inception through handover, but not on the complete project lifecycle.

\subsection{Conclusion}

The study examined the projects' ability to prevent and treat project issues in advance by examining their ability to predict and treat issues. Most project issues were anticipated by thoroughly reviewing the project's challenges and thoroughly understanding the stakeholder factor during the project's early stages. Despite the project's ability to recommend effective treatments, most anticipated project issues were not addressed due to inevitable roadblocks. The projects took no action to address the anticipated issues, and it was left to project operations to resolve them later. In summary, the project issues could have been controlled before their occurrence but were allowed to occur. It was compromising the project's objectives due to inadequate or non-treatment before the occurrence of the issues.

This study recommended that issues be controlled earlier by adopting a management system to predict potential project issues, assess their consequences, and treat them systemically to achieve the project's objective. This systematic process is referred to as risk management. Risk management should improve control over project issues in advance by identifying, assessing, and treating them early. This application will resolve project issues more quickly and more manageable. Controlling project issues enables the achievement of project objectives, thereby enhancing project performance. It will directly enhance the landscape environment to improve dwellers' quality of life.

It is recommended that additional research be conducted on risk management practices in landscape architecture projects. Landscape architecture project practitioners must manage risk to effectively minimise project issues in the future. 


\section{Acknowledgement}

We are grateful to Geran Putra - Inisiatif Putra Siswazah (GP-IPS), Universiti Putra Malaysia, for financial support for this study (Project Number: GP-IPS/2018/9617500).

\section{Article Contribution to Related Field of Study}

This study strengthens lessons learned to improve the landscape architecture body of knowledge, the controllability of project issues, improve project practitioners work culture, and prepare for future endeavours. Additionally, the research will yield a practical contribution by providing insights into applying risk management to landscape project management.

\section{References}

Abdul-Rahman, H., Wang, C., \& Mohamad, F. S. (2015). Implementation of Risk Management in Malaysian Construction Industry: Case Studies. Journal of Construction Engineering, 2015(1), 7. https://doi.org/10.1155/2015/192742

Adnan, H., \& Rosman, M. R. (2018). Risk management in Turnkey projects in Malaysia. WSEAS Transactions on Business and Economics, 15, 35-43.

Ansah, R. H., Sorooshian, S., Mustafa, S. Bin, \& Duvvuru, G. (2016). Assessment of Environmental Risks in Construction Projects: A Case of Malaysia. Proceedings of the International Conference on Industrial Engineering and Operations Management, 752-763.

APM. (2006). APM Body of Knowledge. In Reprinted 2006, 2007 (twice), 2008 (three times), 2009 (twice) (5th ed.). Association for Project Management. https://doi.org/10.1080/10894160.2010.508411

Baker, E. (2007). You've got way too many issues! PMI® Global Congress 2007-North America, 1-6. https://www.pmi.org/learning/library/project-risk-management-issues-management-7267

Bugayenko, Y. (2019). Cause + Risk + Effect. Orsk.com. https://www.yegor256.com/2019/05/14/cause-riskeffect.html

Fadzil, N. S., Noor, N. M., \& Rahman, I. A. (2017). Need of risk management practice amongst bumiputera contractors in Malaysia construction industries. IOP Conference Series: Materials Science and Engineering, 271(012035), 7. https://doi.org/10.1088/1757-899X/271/1/012035

Farooq, M. U., Thaheem, M. J., \& Arshad, H. (2018). Improving the risk quantification under behavioural tendencies: A tale of construction projects. International Journal of Project Management, 36(3), 414-428. https://doi.org/10.1016/j.jproman.2017.12.004

Goh, C. S., \& Abdul-Rahman, H. (2013). The Identification and Management of Major Risks in Malaysian Construction Indusrty. Journal of Construction in Developing Countries, 18(1), 19-32.

Hasan, R., Othman, N., \& Ismail, F. (2018). Choosing Tree for Urban Fabric: Role of Landscape Architect. 6th AicQoL2018Perhentianlsland, 03-04 March 2018 / E-BPJ, 3(7), 199-207.

Hillson, D. (2018). When is a Risk not Risk? The International Association for Contract \& Commercial 
Management. https://journal.iaccm.com/contracting-excellence-journal/when-is-a-risk-not-a-risk

Jusoff, K., Yusuwan, N. M., Adnan, H., \& Omar, A. F. (2008). Clients' Perspectives of Risk Management Practice in Malaysian Construction Industry. Journal Politic and Law, 1(3), 121-130. https://doi.org/10.5539/jpl.v1n3p121

Maguire, M., \& Delahunt, B. (2017). Doing a Thematic Analysis: A Practical, Step-by-Step. The All Ireland Journal of Teaching and Learning in Higher Education, 8(3), 3351-33514. http://ojs.aishe.org/index.php/aishej/article/view/335

Mayring, P. (2014). Qualitative Content Analysis: Theoretical Foundation, Basic Procedures and Software Solution. Social Science Open Access Repository (SSOAR). https://doi.org/http://dx.doi.org/10.4135/9781446282243.n12

McNamara, C. (2017). Field Guide to Nonprofit Program Design, Marketing and Evaluation (5th ed.). Authenticity Consulting, LLC.

OGC. (2009). An Introduction to PRINCE2: Managing and Directing Successful Projects. The Stationery Office (TSO). www.best-management-practice.com

PMI. (2004). A Guide To The Project Management Body Of Knowledge (PMBOK Guide) (PMBOK (ed.); 3rd ed.). Project Management Institute, Inc. https://doi.org/10.1016/0263-7863(95)00006-C

PMI. (2009). Practice standard for project risk management. In Project Management Institute, Inc. (PMI). http://app.knovel.com/web/toc.v/cid:kpPSPRM002

PMI. (2017). A Guide To The Project Management Body Of Knowledge (PMBOK Guide) (PMBOK (ed.); 6th ed.). Project Management Institute, Inc. https://doi.org/10.1002/pmj.21345

PRINCE2. (2017). Managing Successful Projects With PRINCE2 (6th ed.). The Stationery Office (TSO). www.tsoshop.uk

Razi, P. Z., Ali, M. I., \& Ramli, N. I. (2020). Incorporation of Risk Index for Risk Response and Risk Mitigation Strategies of Public-Private Partnership (PPP) Housing Construction Project in Malaysia. IOP Conference Series: Materials Science and Engineering, 712, 012031. https://doi.org/10.1088/1757-899x/712/1/012031

S.Muthuveeran, A. A., Mohd Tahir, O., Ibrahim, R., \& Abd-Karim, S. B. (2020). Reviewing Risk Process Integration Effectiveness into Malaysia's Landscape Architecture Project Lifecycle. Environment-Behaviour Proceedings Journal (E-BPJ), 5(13), 245-255. https://doi.org/10.21834/e-bpj.v5i13.1991

Schatz, A. P. (2003). Regulation Of Landscape Architecture And The Protection Of Public Health, Safety, And Welfare (2003rd ed.). The American Society of Landscape Architects. https://doi.org/10.3934/publichealth.2014.1.9

Spacey, J. (2016). Risk vs Issue. Simplicable. https://simplicable.com/new/risk-vs-issue

Tserng, H. P., Yin, S. Y. L., Dzeng, R. J., Wou, B., Tsai, M. D., \& Chen, W. Y. (2009). A study of ontology-based risk management framework of construction projects through project life cycle. Automation in Construction, 18(7), 994-1008. https://doi.org/10.1016/j.autcon.2009.05.005

Williams, S. K. (2019). Landscape Architecture Body of Knowledge Study Report. www.asla.org/uploadedFiles/CMS/Education/Accreditation/LABOK_Report_with_Appendices.pdf 